\title{
Dicle Nehri'nden Toplanan Unio mancus ve Anodonta anatina Türlerinde Ağır Metal Birikiminin Araştırılması
}

\author{
Çiğdem KAYMAK ABAY ${ }^{1}$
}

\section{ÖZET}

Bu çalışmada, Dicle Nehri'nden 2013-2014 yılları arasında toplanan Unio mancus ve Anodonta anatina türlerinin iç organ kitlesinde $\mathrm{Cu}, \mathrm{Ni}, \mathrm{Co}, \mathrm{Zn}, \mathrm{Cd}$ ve Pb'nun birikim düzeyinin tespit edilmesi amaçlanmıştır. Bu amaçla belirlenen üç istasyondan alınan 90 adet midye örneğinde ağır metal analizi ICP-OES ile yapılmıştır. Unio mancus türünde ölçülen ağır metal konsantrasyonları Zn $(94.2 \mathrm{ppm})>\mathrm{Cu}(31.66 \mathrm{ppm})>\mathrm{Ni}(14.10 \mathrm{ppm})>\mathrm{Pb}(5.72 \mathrm{ppm})>$ Co (2.51 ppm) olmak üzere en yüksek değerlerin (Zn hariç) I. istasyonda olduğu görülmüştür. Zn metalinin en yüksek değeri ise II. istasyonda 107.86 ppm olarak ölçülmüştür. Anodonta anatina türünde I. ve II. istasyonda konsantrasyonlar $\mathrm{Zn}>\mathrm{Cu}>\mathrm{Ni}>\mathrm{Pb}>\mathrm{Co}$, III. istasyonda ise $\mathrm{Zn}>\mathrm{Ni}>\mathrm{Cu}>\mathrm{Pb}>\mathrm{Co}$ olarak ölçülmüştür. $\mathrm{Cu}(23.75$ ppm), Ni (16.06 ppm), Co (3.05 ppm), Pb (3.84 ppm) metallerinin en yüksek değerleri I. istasyonda, Zn (117.68 ppm) metalinin ise en yüksek değeri III. istasyonda ölçülmüştür. İstatistik hesabı ANOVA-Tukey testi ile yapılmış ve ağır metal konsantrasyonları Unio mancus türünde $\mathrm{Cu}(\mathrm{F}=74.238 ; \mathrm{P}=0.000), \mathrm{Ni}(\mathrm{F}=39.584 ; \mathrm{P}=0.000), \mathrm{Co}(\mathrm{F}=13.738$; $\mathrm{P}=0.000) ;$ Anodonta anatina türünde ise $\mathrm{Cu}(\mathrm{F}=35.369 ; \mathrm{P}=0.000), \mathrm{Ni}(\mathrm{F}=20.107 ; \mathrm{P}=0.000), \mathrm{Co}(\mathrm{F}=6.777 ; \mathrm{P}=0.004)$, $\mathrm{Zn}(\mathrm{F}=16.298 ; \mathrm{P}=0.000)$ ve $\mathrm{Pb}(\mathrm{F}=16.347 ; \mathrm{P}=0.000)$ şeklinde anlamlı bulunmuştur $(\mathrm{p}<0.05)$. Çalışmamızda elde edilen ağır metal düzeyleri ülkemizde çift kabuklu yumuşakçalarda Türk Gıda Kodeksi Bulaşanlar Yönetmeliği’ne (2011) göre kabul edilir değerlerin üzerinde, EPA ve FAO’ya göre belirlenen sınır değerlerin ise altında olduğu görülmüştür.

Anahtar Kelimeler: A ̆̆ır metal, Anodonta anatina, Dicle Nehri, Unio mancus

\section{Investigation of Heavy Metal Accumulation in Unio mancus and Anodonta anatina Species Obtained from the Tigris River}

\begin{abstract}
In this study, it was aimed that to determine the accumulation levels of $\mathrm{Cu}, \mathrm{Ni}, \mathrm{Co}, \mathrm{Zn}, \mathrm{Cd}$ and $\mathrm{Pb}$ in the Unio mancus and Anodonta anatina species visceral mass which collected from Tigris River between 2013-2014. For this reason, heavy metal analysis of 90 mussels samples which taken from three stations were carry out by ICPOES. Heavy metal concentrations were measured in the Unio mancus species $\mathrm{Zn}(94.2 \mathrm{ppm})>\mathrm{Cu}(31.66 \mathrm{ppm})>$ $\mathrm{Ni}(14.10 \mathrm{ppm})>\mathrm{Pb}(5.72 \mathrm{ppm})>\mathrm{Co}(2.51 \mathrm{ppm})$ maximum value (except $\mathrm{Zn})$ was found in the first station. The highest value of $\mathrm{Zn}$ was measured in II. station as $107.86 \mathrm{ppm}$. In Anodonta anatina species the concentration of $\mathrm{Zn}>\mathrm{Cu}>\mathrm{Ni}>\mathrm{Pb}>\mathrm{Co}$ at I. and II. station; and $\mathrm{Zn}>\mathrm{Ni}>\mathrm{Cu}>\mathrm{Pb}>\mathrm{Co}$ at III. station were measured. The highest values of $\mathrm{Cu}(23.75 \mathrm{ppm}), \mathrm{Ni}(16.06 \mathrm{ppm}), \mathrm{Co}(3.05 \mathrm{ppm})$ and $\mathrm{Pb}(3.84 \mathrm{ppm})$ were measured in the I. station ; the highest values of $\mathrm{Zn}(117.68 \mathrm{ppm})$ was measured in the III. station. Statistical calculations made with ANOVATukey test and heavy metal concentrations were found significant of $\mathrm{Cu}(\mathrm{F}=74.238 ; \mathrm{P}=0.000), \mathrm{Ni}(\mathrm{F}=39.584$; $\mathrm{P}=0.000), \mathrm{Co}(\mathrm{F}=13.738 ; \mathrm{P}=0.000)$ in Unio mancus species; in Anodonta anatina species, $\mathrm{Cu}(\mathrm{F}=35.369 ; \mathrm{P}=0.000)$, $\mathrm{Ni}(\mathrm{F}=20.107 ; \mathrm{P}=0.000), \mathrm{Co}(\mathrm{F}=6.777 ; \mathrm{P}=0.004), \mathrm{Zn}(\mathrm{F}=16.298 ; \mathrm{P}=0.000)$ and $\mathrm{Pb}(\mathrm{F}=16.347 ; \mathrm{P}=0.000)(\mathrm{p}<0.05)$. The heavy metal levels obtained from the present study, are higher than the accepted values according to Turkish Food Codex Contaminants Regulation (2011) and below the limit values determined according to EPA and FAO in bivalve.
\end{abstract}

Keywords: Heavy metal, Anodonta anatina, Tigris River, Unio mancus

Çiğdem KAYMAK ABAY (0000-0002-4827-8488), Dicle Üniversitesi, Fen Bilimleri Enstitüsü, Biyoloji, Diyarbakır, Türkiye

Sorumlu yazar/Corresponding Author: Çiğdem KAYMAK ABAY, kaymakcigdem@gmail.com 


\section{GİRIŞ}

Kentsel yaşamın başlaması ile ortaya çıkan ve endüstrinin gelişmesiyle artmaya başlayan çevre kirliliği etkisini en çok sucul sistemlerde göstermektedir (Sartor et al, 1974; Kaya ve ark., 1998). Ülkemizde giderek artan problemlerin başında da ağır metal iyonlarından kaynaklanan su kirliliği gelmektedir (Karadede and Ünlü, 2000; Çavuşoğlu ve ark., 2007). Sucul ortamların kirlenmesiyle bu ortamda yaşayan canlı organizmalarda ağır metal birikebilmektedir. Bu metallerin canlılar üzerinde meydana getirdiği değişimlere yönelik çalışmalar artış göstermektedir (Sağlamtimur et al., 2003; Farkas et al., 2003; Canlı and Atlı, 2003; Canpolat and Çalta, 2003; Karadede et al., 2004; Guevara et al., 2004; Kalay et al., 2004; Argese et al., 2005; Yılmaz, 2006; Demirak et al., 2006; Kir et al., 2006; TekinÖzan and Kır, 2006; Velcheva, 2006). Dolayısıyla sucul ortamlarda yaşayan canlılar metal kirliliğini göstermesi açısından indikatör türler olarak değerlendirilmektedir. Bentik organizma olan midyeler sularda bol miktarda bulunmaları, metalleri yüksek yoğunluklarda biriktirip bunları uzun bir süre bünyelerinde tutmalarından dolayı, sularda kirliliği yansıtan biyolojik indikatörlerin başında gelir (Uzunören, 1987; Uzun, 1993; Şentürk, 1993; Naimo, 1995; Öktener, 2004; Taylan ve Özkoç, 2007; Grabarkiewicz and Davis, 2008; Hongyi et al., 2009; Mendil et al., 2010). Çalışmamızda, doğal ve antropojenik çevresel faktörlerin etkisi altında kalan Dicle Nehri'nin belirlenen üç istasyonundan belli aralıklarla alınan Unio mancus (Lamarck, 1819), Anodonta anatina (Linnaeus, 1758) türlerinde $\mathrm{Cu}$, $\mathrm{Ni}, \mathrm{Co}, \mathrm{Zn}, \mathrm{Cd}$ ve $\mathrm{Pb}$ gibi ağır metallerin birikim düzeylerinin belirlenmesi amaçlanmıştır. Lokaliteler arasında elde ettiğimiz değerler istatistiksel olarak karşılaştırılıp hangi bölgenin daha fazla kirlenmeye maruz kaldığı belirlenmeye çalışılmıştır.

\section{MATERYAL VE YÖNTEM}

Eylül 2013’te başlamış olan arazi çalışmaları 2014 Eylül ayına kadar düzenli aralıklarla sürdürülmüştür. Çalışma Dicle Nehri üzerinde belirlenen üç istasyon üzerinde gerçekleştirilmiştir. $\mathrm{Bu}$ istasyonlar belirlenirken nehrin çevresinde yerleşim yeri ve tarım alanlarının olduğu yerler dikkate alınarak örnekler alınmıştır. Çalışma alanının haritası Şekil 1'de verilmiştir.

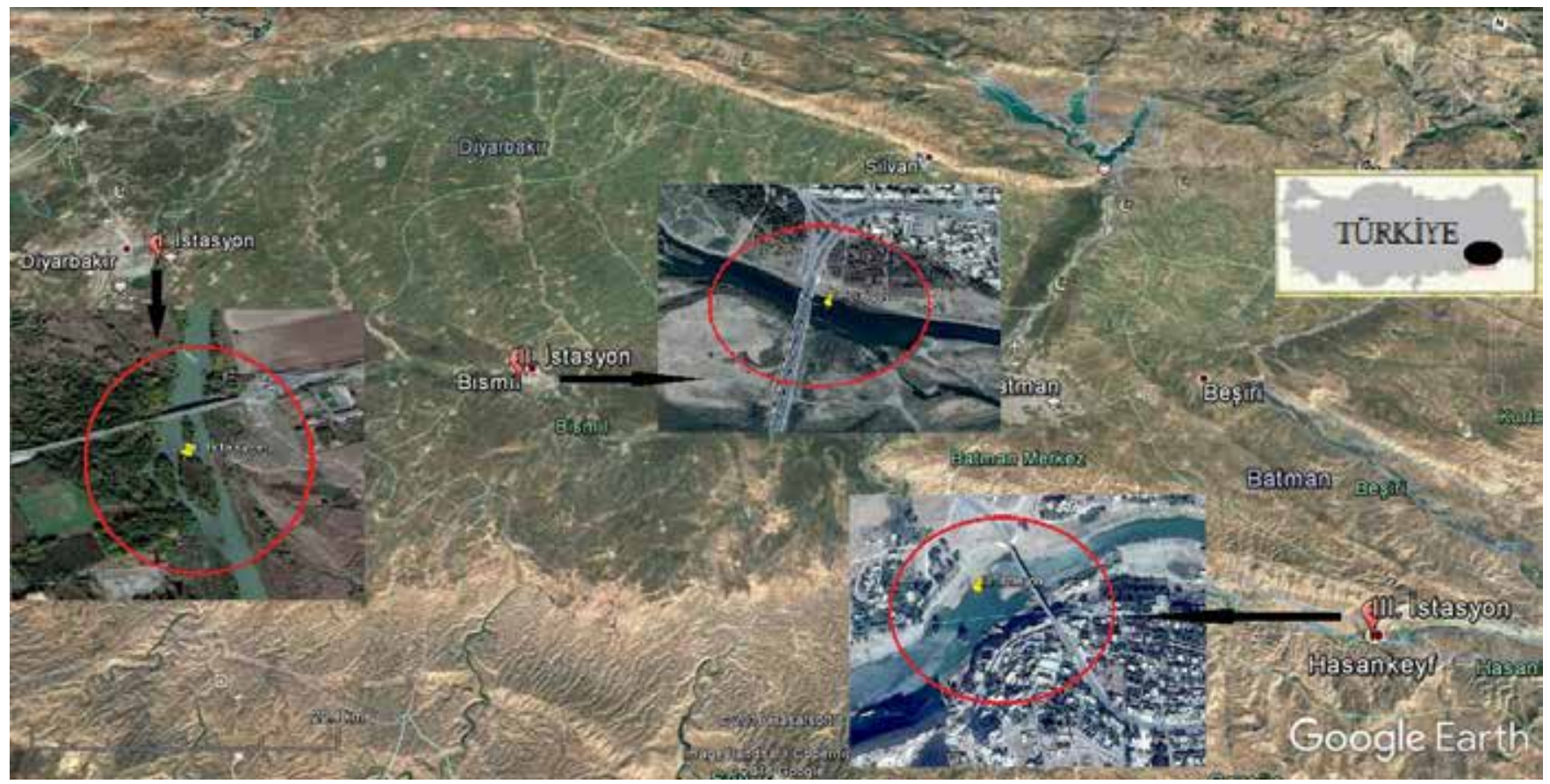

Şekil 1. Dicle Nehri üzerinde örnekleme yapılan istasyonlar

İstasyonlardan alınan midye örnekleri tür seviyesinde teşhis ve sayımları yapılarak ayrı ayrı poşetlere konulmuş ve içinde buz kalıplarının bulunduğu dikdörtgen şekilli üstten blok kapaklı 30
L hacimli termoslarla aynı gün içinde laboratuara getirilmiştir. Birçok çalışmada Unio mancus (Lamarck, 1819) türü Unio elongatulus (Pfeiffer, 1825) olarak, Anodonta anatina (Linneaus,1758) türü de Anodonta 
piscinalis (Nilsson, 1823) olarak kabul edilmektedir. $\mathrm{Bu}$ türlerin bilimsel adı üzerindeki tartışmalar sürmektedir (Lopes-Lima et al., 2016). Çalışmamızda bu türleri Unio mancus ve Anodonta anatina olarak ele aldık. Öncelikle Unio mancus ve Anodonta anatina örneklerine ait uzunluk ölçümleri bir kumpas yardımı ile alınmıştır. Total ağırlıkları ise $0.001 \mathrm{~g}$ hassasiyetli dijital elektronik terazi ile ölçülmüştür. Her istasyondan yaş ve ağırlıkları birbirine yakın olan 15 er adet midye örneği analize hazırlanmıştır. Midyelerin kabukları bir pens yardımıyla açılarak iç organ kitlesi dikkatli bir biçimde alınarak dissekte edilmiştir. $0.001 \mathrm{~g}$ hassasiyetli dijital elektronik terazi ile darası alınmış ısıdan etkilenmeyen polietilenli steril kaplara aktarılan numunelerin yaş ağırlıkları ölçülmüştür. Baget yardımıyla homojen hale getirilen örnekler etüvde yaklaşık $80-85^{\circ} \mathrm{C}$ 'de 72 saat bekletilerek kurumaları sağlanmıştır. Sabit kuru ağırlığa getirilen örneklerin kuru ağırlıkları tartılmış, kayıp olmaması için bulunduğu kap içerisinde dövülerek tamamen homojenize edilmiştir. Tekrar sabit kuruluğa gelmesi için etüvde 1 saat bekletilmiş ve analiz işlemine kadar nem kapmalarını önlemek amacıyla vakumlu poşetlerde bekletilmiştir. Analiz işlemine başlamadan önce midye türlerinin asit eşliğinde parçalanmasını sağlamak amaciyla Berghof marka Speedwave MWS-3+ Mikrodalga çözünürleştirme cihazı kullanılmıştır. Numunelerde bulunan metal konsantrasyonlarını ölçmek amacıyla da Perkin Elmer Optima 2100 DV markalı ICP-OES cihazı kullanılmıştır.
Çözünürleştirme işlemi için hassas terazi yardımıyla bütün numunelerden yaklaşık 0.1-0.2 $\mathrm{g}$ alınarak mikrodalga çözünürleştirme tüplerine yerleştirilmiştir. Her bir tüpün üzerine $5 \mathrm{ml} \mathrm{HNO}_{3}$ ve 1 $\mathrm{ml} \mathrm{H}_{2} \mathrm{O}_{2}$ ilave edilmiş, buhar ve gaz çıkışının sağlanması amaciyla çeker ocakta bir süre bekletilmiştir. İçinde numunelerin bulunduğu 12 adet tüp mikrodalga fırınına yerleştirilerek çözünürleştirme işlemi başlatılmıştır. Mikrodalga fırınında $40 \mathrm{dk}$ çözünürleştirme işlemi yapıldıktan sonra cihazdan çıkarılan tüplerin oda sıcaklığında soğumaları sağlanmıştır. Soğuyan tüplerin kapakları açılmış, tüplerdeki çözelti filtre edilerek falkon tüplerine aktarılmış ve çözelti miktarı ultra saf su ile seyreltilerek 15 mL'ye tamamlanmıştır. $\mathrm{Cu}, \mathrm{Ni}, \mathrm{Co}$, $\mathrm{Cd}, \mathrm{Pb}$ ağır metalleri için 0.025, 0.05, 0.1, 0.3, 0.5, 1, $1.5 \mathrm{ppm}$ konsantrasyonlarda, $\mathrm{Zn}$ metali için $0.5,1,1.5$, 2, 2.5 ppm standartlarda çözeltiler hazırlanmıştır. Bu standartlar 1000 ppm'lik stok çözeltiden seyreltmeler yoluyla hazırlanmıştır. Sonuçlar kuru ağırlık üzerinden $\mathrm{mg} \mathrm{kg}^{-1}$ olarak hesaplanmıştır.

\section{BULGULAR VE TARTIŞMA}

Midye türlerinde yaptığımız çözünürleştirme ve analiz sonuçlarının doğruluğundan emin olabilmek için standart referans materyal olarak NRC-CNRC DOLT3 kullanılmış ve sonuçlar Çizelge 1'de verilmiştir. En yükssek uyumluluk \% 109 ile $\mathrm{Zn}$ da, en düşük uyumluluk ise \% 83 ile $\mathrm{Cd}$ metalinde ölçülmüşsür.

Çizelge 1. NRC-CNRC DOLT-3 standart referans materyal ile ölçülen değerler

\begin{tabular}{|l|c|c|c|}
\hline Metaller & Referans Değerler $\left(\mathbf{m g ~ k g}^{-1}\right)$ & $\begin{array}{c}\text { Ölçülen Değerler } \\
\left(\mathbf{m g ~ k g}^{-1}\right)\end{array}$ & Uyumluluk (\%) \\
\hline $\mathrm{Cu}$ & $31.2 \pm 1.0$ & $30.53 \pm 0.22$ & 97 \\
\hline $\mathrm{Ni}$ & $2.72 \pm 0.35$ & $2.42 \pm 0.007$ & 89 \\
\hline $\mathrm{Zn}$ & $86.6 \pm 2.4$ & $94.4 \pm 1.05$ & 109 \\
\hline $\mathrm{Cd}$ & $19.4 \pm 0.6$ & $16.25 \pm 0.19$ & 83 \\
\hline
\end{tabular}

Çalışılan istasyonlardan alınan Unio mancus türünde ölçülen ağır metal konsantrasyonlarının değişimi (ortalama değer, standart sapma, minimummaksimum değerleri ile istatistiksel farklılıkları) Çizelge 2'de, bölgeler arasındaki ortalama metal konsantrasyonlarının değişim grafikleri ise Şekil 2'de verilmiştir. Unio mancus türünde istasyonlar arasında ağır metal birikim oranları değerlendirildiğinde $\mathrm{Cu}$,
Co ve $\mathrm{Pb}$ metalleri $\mathrm{I}>\mathrm{II}>\mathrm{III}$; Ni metali $\mathrm{I}>\mathrm{III}>\mathrm{II}$; $\mathrm{Zn}$ metali ise II $>$ III $>$ I olarak ölçülmüsştür. $\mathrm{Cu}, \mathrm{Ni}$ ve Co metallerinde istasyonlar arasinda $\mathrm{Cu}(\mathrm{F}=74.238$; $\mathrm{P}=0.000), \mathrm{Ni}(\mathrm{F}=39.584 ; \mathrm{P}=0.000)$, Co $(\mathrm{F}=13.738$; $\mathrm{P}=0.000)$ şeklinde anlamlı bir farklılık olduğu $(\mathrm{p}<0.05)$; $\mathrm{Zn}$ ve $\mathrm{Pb}$ metalinde anlamlı bir şekilde farklılık olmadı $\breve{g}_{1}$ görülmüştür ( $\mathrm{p}>0.05)$. 
Çizelge 2. Unio mancus türünde ölçülen ağır metal konsantrasyonlarının istasyonlara göre değişimi (Ortalama değer \pm Standart sapma, Minimum-Maksimum değerleri ile istatistiksel farklılıkları)

\begin{tabular}{|c|c|c|c|c|c|c|c|c|}
\hline & $\mathbf{N}$ & İstasyonlar & $\mathbf{C u}$ & $\mathbf{N i}$ & Co & $\mathbf{Z n}$ & Cd & $\mathbf{P b}$ \\
\hline \multirow{3}{*}{ 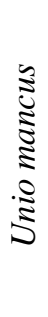 } & 15 & $\begin{array}{l}\text { I. İstasyon } \\
\text { (Diyarbakır) }\end{array}$ & $\begin{array}{l}31.66 \pm 9.34^{\mathrm{a}} \\
(19.14-49.6)\end{array}$ & $\begin{array}{l}14.10 \pm 3.18^{a} \\
(9.27-19.9)\end{array}$ & $\begin{array}{l}2.51 \pm 0.6^{\mathrm{a}} \\
(1.18-3.6)\end{array}$ & $\begin{array}{l}94.20 \pm 18.25^{\mathrm{a}} \\
(70.95-136.5)\end{array}$ & ALA & $\begin{array}{l}5.72 \pm 2.32^{\mathrm{a}} \\
(4.03-12.7)\end{array}$ \\
\hline & 15 & $\begin{array}{l}\text { II. İstasyon } \\
\text { (Bismil) }\end{array}$ & $\begin{array}{l}12.07 \pm 3.71^{b} \\
(6.5-17.78)\end{array}$ & $\begin{array}{l}6.22 \pm 2.68^{b} \\
(3.77-14.2)\end{array}$ & $\begin{array}{l}1.5 \pm 0.73^{b} \\
(0.93-3.1)\end{array}$ & $\begin{array}{l}107.86 \pm 39.41^{\mathrm{a}} \\
(63.61-202.5)\end{array}$ & ALA & $\begin{array}{l}5.16 \pm 4.31^{\mathrm{a}} \\
(2.38-17.5)\end{array}$ \\
\hline & 15 & $\begin{array}{l}\text { III. İstasyon } \\
\text { (Hasankeyf) }\end{array}$ & $\begin{array}{l}6.41 \pm 2.32^{c} \\
(3.55-10.16)\end{array}$ & $\begin{array}{l}7.29 \pm 1.84^{\mathrm{b}} \\
(4.49-10.7)\end{array}$ & $\begin{array}{l}1.4 \pm 0.28^{\mathrm{b}} \\
(1.08-1.9)\end{array}$ & $\begin{array}{l}103.4 \pm 38.27^{\mathrm{a}} \\
(64.34-182.6)\end{array}$ & ALA & $\begin{array}{l}3.92 \pm 2.39^{\mathrm{a}} \\
(1.92-11.5)\end{array}$ \\
\hline
\end{tabular}

N: Çalışılan tür sayısı

Unio mancus türünde aynı sütundaki farklı harfler farkın istatistiksel olarak önemli olduğunu ifade etmektedir (p<0.05). a, b, c harfleri istasyonlar arasındaki farklılı̆̆ gösterir

ALA: Ölçümler ICP-OES'in analiz limitinin altındadır. Cd için bu değer $0.012 \mathrm{mg} \mathrm{L}^{-1}$ olarak ölçülmüştür

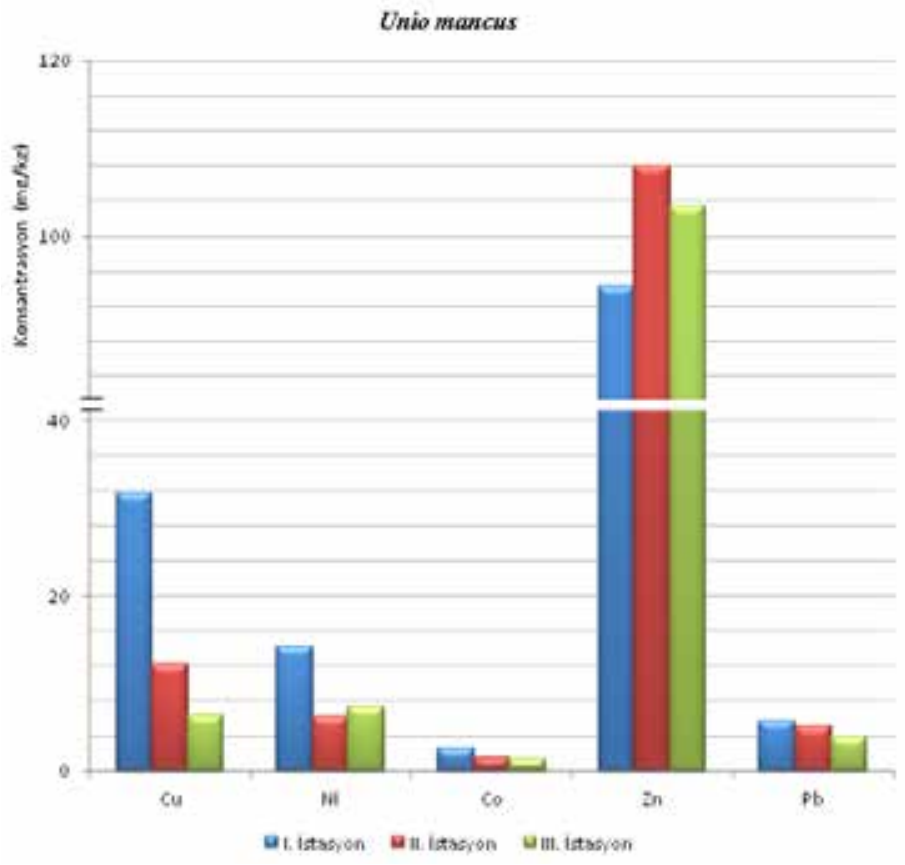

Şekil 2. Unio mancus türünde ölçülen ağır metal konsantrasyonlarının istasyonlara göre değişim grafiği

Karadede (2002) Dicle Nehri'nde Unio elongatulus türü üzerinde yapmış olduğu çalışmada konsantrasyonları $\mathrm{Cu}: 4.43, \mathrm{Zn}: 9.24$, Ni: $0.67 \mu \mathrm{g}$ $\mathrm{g}^{-1}$ şeklinde bulmuştur. Yarsan ve ark. (2000) Van Gölü'nden toplanan Unio stevenianus Krynicki örneklerinde ağır metal düzeylerini belirlemek amaciyla yaptıkları çalışmada analiz edilen bütün midyelerde $\mathrm{Pb}: 1.43 \pm 0.81 \mathrm{ppm}, \mathrm{Cd}: 0.09 \pm 0.02$ ppm $, \mathrm{Cu}: 5.83 \pm 0.73$ ppm, Zn: $15.93 \pm 3.26$ ppm olarak tespit etmişlerdir. Şahin ve ark. (2016) Karakaya Baraj Gölü'nde Unio elongatulus eucirrus türünde ağır metal düzeylerinin belirlenmesi için biri referans olarak seçilen Arguvan, diğeri kirliliğe maruz kalan Battalgazi olmak üzere iki farklı istasyon belirlemişlerdir. Elde ettikleri verilere göre, midyelerin kas dokusunda ağır metallerin derişim düzeyleri sırasıyla Arguvan bölgesinde $\mathrm{Cd}$ (0.146)> $\mathrm{Pb}(0.089)>\mathrm{Ni}(2.67)>\mathrm{Zn}(1.13)>\mathrm{Cu}(0.22)$, Battalgazi bölgesinde $\mathrm{Cd}(0.136)>\mathrm{Pb}(0.062)>\mathrm{Co}$ $(0.68)>\mathrm{Ni}(2.31)>\mathrm{Cu}(0.96)>\mathrm{Zn}(0.34)$ ppm olarak tespit etmişlerdir. Yılmaz (2011) Dipsiz Çine Çayı'nda Unio crassus türünün kas, manto ve solungaçlarında total metal konsantrasyonunu ppm olarak Zn (24.24)> 
$\mathrm{Ni}(1.32)>\mathrm{Cu}(0.72)>\mathrm{Pb}(0.29)>\mathrm{Cd}(0.23)$ şeklinde ölçmüşlerdir. Tüm bu çalışmalarda da görüldüğü gibi Unio cinsi midyelerde ölçülen ağır metal değerleri çalışmamıza göre daha düşük konsantrasyonlardadır.

Anodonta anatina türünde ölçülen ağır metal konsantrasyonlarının değişimi (ortalama değer, standart sapma, minimum-maksimum değerleri ile istatistiksel farklılıkları) Çizelge 3'te, istasyonlar arasındaki ortalama metal konsantrasyonlarının değişim grafikleri ise Şekil 3 ’te verilmiştir. Anodonta anatina türünde istasyonlar arasında ağır metal birikimi değerlendirildiğinde $\mathrm{Cu}$ ve $\mathrm{Ni}$ konsantrasyonu I $>$ II $>$ III; Co konsantrasyonu I> III > II; Zn konsantrasyonu III $>\mathrm{II}>\mathrm{I}$; $\mathrm{Pb}$ konsantrasyonu ise II > I> III olarak ölçülmüsştür. $\mathrm{Cu}, \mathrm{Ni}, \mathrm{Co}, \mathrm{Zn}$ ve $\mathrm{Pb}$ konsantrasyonlarında istatistiksel olarak önemli bir farka sahip olduğu görülmüştür $(\mathrm{p}<0.05) . \mathrm{Cu}$ $(\mathrm{F}=35.369 ; \mathrm{P}=0.000), \mathrm{Ni}(\mathrm{F}=20.107 ; \mathrm{P}=0.000)$, Co $(\mathrm{F}=6.777 ; \mathrm{P}=0.004), \mathrm{Zn}(\mathrm{F}=16.298 ; \mathrm{P}=0.000)$ ve $\mathrm{Pb}$ $(\mathrm{F}=16.347 ; \mathrm{P}=0.000)$ şeklinde anlamlı bulunmuştur.

Çizelge 3. Anodonta anatina türünde ölçülen ağır metal konsantrasyonlarının istasyonlara göre değişimi (Ortalama değer \pm Standart sapma, Minimum-Maksimum değerleri ile istatistiksel farklılıkları)

\begin{tabular}{|c|c|c|c|c|c|c|c|}
\hline$N=15$ & İstasyonlar & $\mathbf{C u}$ & $\mathbf{N i}$ & Co & $\mathbf{Z n}$ & Cd & $\mathbf{P b}$ \\
\hline \multirow{3}{*}{ 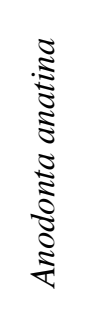 } & $\begin{array}{l}\text { I. İstasyon } \\
\text { (Diyarbakır) }\end{array}$ & $\begin{array}{c}23.75 \pm 9.60^{a} \\
(12.7-52.1)\end{array}$ & $\begin{array}{l}16.06 \pm 5.68^{\mathrm{a}} \\
(8.85-29.3)\end{array}$ & $\begin{array}{l}3.05 \pm 1.22^{\mathrm{a}} \\
(1.26-5.96)\end{array}$ & $\begin{array}{l}66.29 \pm 10.44^{\mathrm{a}} \\
(53.19-90.53)\end{array}$ & ALA & $\begin{array}{c}3.84 \pm 1^{\mathrm{a}} \\
(2.25-5.7)\end{array}$ \\
\hline & $\begin{array}{l}\text { II. İstasyon } \\
\text { (Bismil) }\end{array}$ & $\begin{array}{l}12.52 \pm 2.78^{b} \\
(5.98-16.6)\end{array}$ & $\begin{array}{l}10.23 \pm 2.94^{\mathrm{b}} \\
(5.64-15.6)\end{array}$ & $\begin{array}{l}1.67 \pm 0.67^{\mathrm{b}} \\
(0.64-2.92)\end{array}$ & $\begin{array}{l}102.05 \pm 29.44^{\mathrm{b}} \\
(65.42-181.8)\end{array}$ & ALA & $\begin{array}{r}6.33 \pm 1.93^{\mathrm{b}} \\
(3.45-10)\end{array}$ \\
\hline & $\begin{array}{l}\text { III. İstasyon } \\
\text { (Hasankeyf) }\end{array}$ & $\begin{array}{c}5.5 \pm 2.78^{c} \\
(2.18-10.4)\end{array}$ & $\begin{array}{l}5.46 \pm 4.69^{c} \\
(1.99-21.2)\end{array}$ & $\begin{array}{l}2.35 \pm 1.69^{a b} \\
(1.15-3.55)\end{array}$ & $\begin{array}{l}117.68 \pm 30.65^{\mathrm{b}} \\
(74.90-181.1)\end{array}$ & ALA & $\begin{array}{r}3.42 \pm 1.43^{\circ} \\
(1.46-6.8)\end{array}$ \\
\hline
\end{tabular}

N: Çalışılan tür sayısı

Anodonta anatina türünde istasyonlar arasında aynı sütundaki farklı harfler farkın istatistiksel olarak önemli olduğunu ifade etmektedir (p<0.05). a, b, c harfleri istasyonlar arasındaki farklılı̆̆ı gösterir

ALA: Ölçümler ICP-OES'in analiz limitinin altındadır. Cd için bu değer $0.012 \mathrm{mg} \mathrm{L}^{-1}$ olarak ölçülmüştür

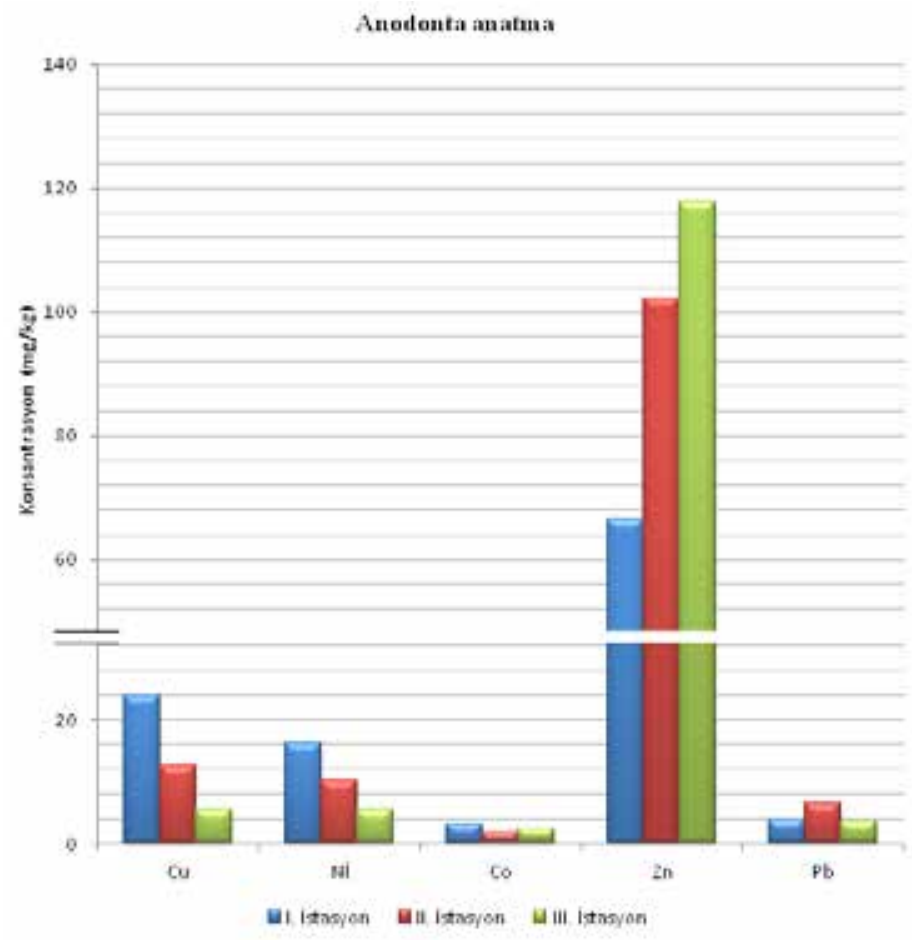

Şekil 3. Anodonta anatina türünde ölçülen ağır metal konsantrasyonlarının istasyonlara göre değişim grafiği 
Baltacı (2011) Çıldır Gölü'nde Anodonta cynea Linnaeus türünde yaptığ 1 çalışmada $\mathrm{Zn}(1.83 \pm 0.61$ ppm $)>\mathrm{Pb}(0.88 \pm 0.49)>\mathrm{Cu}(0.26 \pm 0.03 \mathrm{ppm})>\mathrm{Cd}$ $(0.04 \pm 0.03 \mathrm{ppm})$; Dobrowolski ve Skowrońska (2001) Zemborzyce'de Anodonta sp. türünde yaptığ 1 çalışmada konsantrasyonları $\mathrm{Zn}(18.7 \mathrm{ppm})>\mathrm{Pb}$ $(0.115 \mathrm{ppm})>\mathrm{Cd}(0.051 \mathrm{ppm})$ şeklinde bulmuşlardır. Gundacker (2000) Viyana kentsel nehir habitatında Anodonta sp. ve Unio pictorum türlerinin solungaç ve kas dokularında ağır metal çalışması yapmıştır. Çalışma sonunda Anodonta sp.'nin solungacında $\mathrm{Cd}$ : 0.25-0.67, $\mathrm{Pb}: 1.09-21.3, \mathrm{Cu}: 2.9-8.3$ ve $\mathrm{Zn}: 317-$ 862 ppm, kasinda Cd: 0.16-0.72, Pb: 0.16-3.18, Cu: 0.9-8.5 ve $\mathrm{Zn}: 111-328 \mathrm{ppm}$ ve Unio pictorum'un solungacinda $\mathrm{Cd}$ : $0.3-0.82, \mathrm{~Pb}: 1.13-4.68, \mathrm{Cu}: 7.2-$ 9.2 ve $\mathrm{Zn}: 316-430 \mathrm{ppm}$, kasinda Cd: $0.23-0.9, \mathrm{~Pb}$ : 0.29-2.2, $\mathrm{Cu}: 5.2-6.1$ ve $\mathrm{Zn}: 142-276 \mathrm{ppm}$ olarak bulmuştur. Zn metali değerlerinin çalışmamızdan yüksek, $\mathrm{Cu}, \mathrm{Pb}$ değerlerinin çalışmamıza göre daha düşük değerlerde olduğu görülmüştür. Salanki ve ark. (2003) Macaristan'ın Balaton Gölü'nde Anodonta cygnea türü üzerine yaptıkları çalışmada konsantrasyonları $\mathrm{Cd}$ : 14.7-13.4, $\mathrm{Cu}$ : 10.7-28.3, $\mathrm{Pb}$ : 4.2-12.4 ppm bulmuşlardır. $\mathrm{Pb}, \mathrm{Cu}$ ve $\mathrm{Cd}$ değerlerinin çalışmamıza göre yüksek konsantrasyonda olduğu görülmüştür.

Literatür karşılaştırmalarında da görüldüğü gibi midyelerdeki metal düzeylerinin farklılığı o bölgedeki kirliliğin farklılıklarını ortaya koymaktadır. Ayrıca su ürünleri ve midyelerde ağır metallerde kabul edilebilir maksimum değerler ülkelere göre farklılıklar göstermektedir (Uzun, 1993; Kaya ve ark., 1998; Anonim, 2011). Örneğin midyeler için Finlandiya'da Pb: 2 ppm, İngiltere'de $\mathrm{Pb}: 10 \mathrm{ppm}$ ve $\mathrm{Cu}$ : $20 \mathrm{ppm}$, Venezuella'da ise $\mathrm{Pb}$ : $2 \mathrm{ppm}, \mathrm{Cu}: 10 \mathrm{ppm}$ olarak sınırlandırılmıştır. Türk Gıda Kodeksi Bulaşanlar Yönetmeliği’ne (2011) göre ülkemizde ise çift kabuklu yumuşakçalarda $\mathrm{Pb}: 1.5, \mathrm{Cd}: 1, \mathrm{Cu}: 20, \mathrm{Zn}: 50 \mathrm{mg} \mathrm{\textrm {kg } ^ { - 1 }}$ yaş ağırlık olarak sınırlandırılmıştır. Ni ve Co için yönetmelikte herhangi bir bilgiye rastlanmamıştır. Buda çalışmaların yetersiz boyutlarda olduğunu göstermektedir.

Uluslararası kuruluşlarda ise midyelerde ağır metal limit değerleri şu şekildedir: EPA'ya göre Cd: 1.4, Co: 27, Cu: 54, Ni: 27 ve Zn: 410 ppm (Anonim 2005a); FAO'ya göre yumuşakçalarda kuru ağırlık konsantrasyon değerleri $\mathrm{Cd}$ : $10, \mathrm{Cu}$ : 50-150,
$\mathrm{Pb}:$ 5-30, Zn: 200-500 ppm olarak bildirilmiştir (Wagner and Boman, 2004).

\section{SONUÇ}

Dicle Nehri birçok kirletici unsurun etkisinde bulunmaktadır. Bunlar arasında nehre kıyısı olan yerleşim birimlerinin kanalizasyon suları, sanayi kuruluşları atık suları, çevresinde bulunan petrol kuyuları ve tesislerinde meydana gelen aksaklıklardan dolayı olan sızıntılar nehre karışarak ciddi oranlarda kirliliğe neden olabilirler (Anonim, 2005b). Ayrica belirlenen istasyonlarda tarım alanları ve ticari işletmelerin nehir sistemine yakın olmasının da kirliliğe neden olduğu düşünülmektedir. Dicle Nehri'nin üç istasyonundan toplanan Unio mancus ve Anodonta anatina türlerinde en fazla biriken metalin $\mathrm{Zn}$ en az biriken metalin ise Co olduğu görülmüştür. Zn metalindeki yüksek değerlerin sıcaklığa bağlı olarak metabolik aktivitelerdeki değişiklilerden kaynaklı olduğunu düşünmekteyiz. Cd metalinde ise sonuçlar ICPOES cihazının ölçüm sınırlarının altında kaldığı için tespit edilememiştir. I. istasyonda $\mathrm{Cu}, \mathrm{Pb}$ ve $\mathrm{Zn}$ en fazla Unio mancus'ta, Ni ve Co en fazla Anodonta anatina'da; II. istasyonda $\mathrm{Cu}, \mathrm{Ni}, \mathrm{Co}$ ve $\mathrm{Pb}$ metali en fazla Anodonta anatina'da, $\mathrm{Zn}$ metali ise en fazla Unio mancus'ta; III. istasyonda $\mathrm{Cu}, \mathrm{Ni}$ ve $\mathrm{Pb}$ metallerinde en fazla birikimin Unio mancus'ta; Co ve $\mathrm{Zn}$ ise Anodonta anatina türünde ölçülmüştür. Çalışma bölgelerinde metallerin birikim oranlarının türler arasında farklılıklar gösterdiği görülmüştür. Çalışmamızda elde edilen ağır metal düzeyleri yönetmeliğe göre kabul edilir değerlerin üzerinde, EPA ve FAO'ya göre belirlenen sınır değerlerin ise altında olduğu görülmektedir. Ortamda hiçbir şekilde yok olmayan bu ağır metaller, çeşitli yollarla insanlara da ulaşabilmekte ve insan sağlığını tehdit edecek tehlikeli boyutlara varabilmektedir (Şeker et al., 1998). Tatlısu sisteminin geleceği için önemli olan bu tarz çalışmalar düzenli olarak yapılmalıdır.

\section{TEŞEKKÜR}

$\mathrm{Bu}$ çalışma doktora tezinden üretilmiştir. 12-FF85 No'lu Proje ile çalışmayı maddi olarak destekleyen Dicle Üniversitesi Bilimsel Araştırma Projeleri Yönetim Birimi Başkanlığı'na teşekkür ederim. 


\section{KAYNAKLAR}

Anonim, 2005a. EPA Region III RBC Table. [http://www.epa. gov/reg3hwmd/risk/human/rbc/rbc0405]. (Erişim tarihi: 1 Ağustos, 2016).

Anonim, 2005b. Diyarbakır 2004 İl Çevre Durum Raporu. Diyarbakır Valiliği İl Çevre ve Orman Müdürlüğü (Erişim tarihi: 27 Eylül, 2016).

Anonim, 2011. Türk Gıda Kodeksi Bulaşanlar Yönetmeliği Yetki Kanunu, 2011. 5996 sayılı Resmi Gazete 29.12.2011-28157. (Erişim tarihi: 2 Eylül, 2016).

Argese EC, Bettiol C, Rigo S, Bertini S, Colomban P, Ghetti F, 2005. Distribution of arsenic compound in Mytilus galloprovincialis of the Venice Lagoon, Italy. Science of Total Environment, 15: 267-277.

Baltacı BB, 2011. Çıldır Gölü'nün suyunda, dip sedimentinde ve buradan çıkarılan midyelerde (Anodonta cynea Linnaeus, 1758 ) bazı ağır metallerin derişim düzeylerinin araştırılması. Kafkas Üniversitesi Fen Bilimleri Enstitüsü,Yüksek lisans tezi, 46s.

Canlı M, Atlı G, 2003. The relationships between heavy metal (Cd, $\mathrm{Cr}, \mathrm{Cu}, \mathrm{Fe}, \mathrm{Pb}, \mathrm{Zn}$ ) levels and the size of six Mediterranean fish species. Environmental Politics, 121: 129-136.

Canpolat Ö, Çalta M, 2003. Heavy metals in some tissues and organs of Capoeta capoeta umbla (Heckel 1843) fish species in relation to body size, age, sex and seasons. Fresenius Environmental Bulletin, 12 (9): 961-966.

Çavuşoğlu K, Gündoğan Y, Arıca Ş, Kırındı T, 2007. Mytilus sp (midye), Gammarus sp (nehir tırnağı) ve Cladophora sp (yeşil alg) örnekleri kullanılarak Kızılırmak Nehri'ndeki ağır metal kirliliğin araştırılması. Boğaziçi Üniversitesi Fen Bilimleri Enstitüsü Dergisi, 9 (1): 52-60.

Demirak A, Yılmaz F, Tuna AL, Özdemir N, 2006. Heavy metals in water, sediment and tissues of Leuciscus cephalus from a stream in southwestern Turkey. Chemosphere, 63: 1451-1458.

Dobrowolski R, Skowronska M, 2001. Distribution and environmental mobility of selected trace metals in the Zemborzyce Reservoir. Polish Journal Environmental Studies, 10 (5): 383-388.

Farkas A, Salánki J, Specziár A, 2003. Age-and size specific of heavy metals in the organs of freshwater fish Abramis brama L. populating a low-contaminated site. Water Research, 37: 959-964.

Grabarkiewicz JD, Davis WS, 2008. An Introduction to Freshwater Mussels as Biological Indicators. US Environmental Protection Agency, 108 .

Guevara SR, Bubach D, Vigliano P, Lippolt G, Arribere M, 2004. Heavy metal and other trace elements in native mussel Diplodon chilensis from Northern Patagonia Lakes, Argentina. Biological Trace Element Research, 102: 245-263.

Gundacker C, 2000. Comparioson of heavy metal bioaccumulation in freshwater molluscs of urban river habitats in Vienna. Environmental Pollution, 110: 61-71.

Hongyi N, Wenjing D, Qunhe W, Xingeng C, 2009. Potential toxic risk of heavy metals from sediment of the Pearl River in South China. Journal of Environmental Sciences, 21: 1053-1058.
Kalay M, Koyuncu CE, Dönmez AE, 2004. Comparison of Cd levels in the muscle and liver tissues of Mullus barbatus and Sparus aurata caught from the Mersin Gulf, (In Turkish). Ekoloji Çevre Dergisi, 13: 23-27.

Karadede H, Ünlü E, 2000. Concentrations of some heavy metals in water, sediment and fish species from the Atatürk Dam Lake (Euphrates), Turkey. Chemosphere, 41 (9): 1371-1376.

Karadede H, 2002. Dicle Nehri'nde su, sediment ve bentik bazı canlı organizmalardaki ağır metal birikiminin araştırılması. Dicle Üniversitesi Fen Bilimleri Enstitüsü, Doktora Tezi, 145s.

Karadede H, Oymak SA, Ünlü E, 2004. Heavy metals in mullet, Liza abu, and catfish, Silurus triostegus, from the Atatürk Dam Lake (Euphrates), Turkey. Environment International, 30: $183-188$.

Kaya S, Pirinçci I, Bilgili A, 1998. Çevre Bilimi ve Çevre Toksikolojisi. Medisan Yayın Serisi, Yayın No:36, Ankara, 112s.

Kır İ, Tekin-Özan S, Barlas M, 2006. Heavy metal concentrations in organs of Rudd, Scardinus erythrophthalmus L., 1758 populating Lake Karataş-Turkey. Fresenius Environmental Bulletin, 15 (1): 25-29.

Lopes-Lima M, Sousa R, Geist J, Aldridge CD, Araujo R et al., 2016. Conservation status of freshwater mussels in Europe: state of the art and future challenges. Biological Reviews, 92 (1): $572-607$

Mendil D, Ünal FO, Tüzen F, Soylak M, 2010. Determination of trace metals in different fish species and sediments from the River Yeşilırmak in Tokat, Turkey. Food and Chemical Toxicology, 48: 1383-1392.

Naimo TJ, 1995. A review of the effects of heavy metals on freshwater mussels. Ecotoxicology, 4: 341-362.

Öktener A, 2004. Sinop ve Bafra'da bazı tatlısulardaki mollusca türleri üzerine bir ön araştırma. Gazi University Journal of Science, 17 (2): 21-30.

Sağlamtimur B, Cicik B, Erdem C, 2003. Effects of different concentrations of $\mathrm{Cu}$ alone and $\mathrm{Cu}+\mathrm{Cd}$ mixture on the accumulation of $\mathrm{Cu}$ in the gill, liver, kidney and muscle tissues of Oreochromis niloticus. (In Turkish). Turkish Journal of Veterinary and Animal Sciences, 27: 813-820.

Salánki J, Farkas A, Kamardina T, Rózsa KK, 2003. Molluscs in biological monitoring of water quality. Elsevier, 140 -141 : 403-410.

Sartor JD, Boyd GB, Agardy FJ, 1974. Water pollution aspects of street surface contaminants. Journal (Water Pollution Control Federation), 46 (3): 458-467.

Şahin AG, Sünbül MR, Küçükyılmaz M, 2016. Karakaya Baraj Gölü'ndeki tatlısu midyesi (Unio elongatulus eucirrus Bourguignat 1860)'nin ağır metal düzeylerinin belirlenmesi. Firat Üniversitesi Fen Bilimleri Dergisi, 28(1): 13-19.

Şeker E, Özmen H, Aksoy Ş, 1998. Investigation of heavy metal accumulation in Capoeta capoeta umbla (Heckel, 1843) caught in Elazıg Hazar Lake, (in Turkish). Firat Üniversitesi Fen ve Mühendislik Bilimleri Dergisi, 10 (2): 13-20.

Şentürk F, 1993. Çeşitli yörelerden avlanmış mollusklarda civa, kadmiyum, kurşun düzeylerinin saptanması. İstanbul Üniversitesi Fen Bilimleri Enstitüsü, Yüksek Lisans Tezi, 38s.

Taylan ZS, Özkoç HB, 2007. Potansiyel ağır metal kirliliğinin belirlenmesinde akuatik organizmaların biokullanılabilirliliği. Balıkesir Üniversitesi Fen Bilimleri Enstitüsü Dergisi., 9 (2): 17-33. 
Tekin-Özan S, Kır İ, 2006. Concentrations of some heavy metals in organs of two fish species from the Beyşehir Lake, Turkey. Fresenius Environmental Bulletin, 15(6): 530-534.

Uzun S, 1993. Su ürünlerinin başlıca ağır metallerle kirlenme durumu ve konunun halk sağlı̆̆ 1 yönünden incelenmesi. Ankara Üniversitesi Sağlık Bilim Enstitüsü. Yüksek Lisans Semineri Notlar.

Uzunören N, 1987. Ağır metallerle kirlenmiş sulardan toplanan midyeler ve benzeri deniz ürünlerinde ağır metallerden arsenik ve türevleri ile kirlenme düzeylerinin saptanması. İstanbul Üniversitesi Sağlık Bilimleri Enstitüsü, Doktora Tezi, 101s.

Velcheva IG, 2006. Zinc content in the organs and tissues of freshwater fish from the Kardjali and Studen Kladenets Dam Lakes in Bulgaria. Turkish Journal of Zoology, 30 (1): 1-7.
Wagner A, Boman J, 2004. Biomonitoring of trace elements in Vietnamese freshwater mussels. Spectrochimica Acta Part B, 59: 1125-1132.

Yarsan E, Bilgili A, Türel İ, 2000. Van Gölü'nden toplanan midye (Unio stevenianus krynicki) örneklerindeki ağır metal düzeyleri. Turkish Journal of Veterinary and Animal Sciences, 24: 93-96.

Y1lmaz F, 2006. Bioaccumulation of heavy metals in water, sediment, aquatic plants and tissues of Cyprinus carpio from Kızılırmak, Turkey. Fresenius Environmental Bulletin, 15(5): 360-369.

Yılmaz Ö, 2011. Dipsiz-Çine Çayı (Muğla, Aydın)'ndan alınan su, sediment ve Unio crassus (Bivalvia: Unionidae) örneklerinde ağır metal miktarlarının araştırılması. Muğla Üniversitesi Fen Bilimleri Enstitüsü, Yüksek lisans Tezi, 129s. 